\title{
51 APPLYING ADAPTIVE STRUCTURATION THEORY TO THE STUDY OF CONTEXT-AWARE APPLICATIONS
}

\author{
Carl Magnus Olsson \\ Viktoria Institute \\ Nancy L. Russo \\ Northern Illinois University
}

\begin{abstract}
Adaptive structuration theory (AST) has been used for a number of years in the information systems discipline to study the use of new technologies in organizations. In this paper it is applied to a relatively new technology, context-aware applications. AST provides a useful lens for examining the impact of a particular context-aware application, CABdriver. Used in conjunction with the repertory grid technique and lead users in an action research study, a research approach for exploring the ways in which the technology impacts individuals within small groups is presented.
\end{abstract}

Keywords: Action research, adaptive structuration theory, context-aware applications, lead users, repertory grid technique

\section{INTRODUCTION}

Whereas some strides, particularly in the diversity of research approaches, have been made since the 1984 Manchester Colloquium (Mumford et al. 1985), some things have not changed. It is still true that "The rate at which information technology is being introduced in our institutions exceeds our capacity to generate knowledge about its effects and meanings" (Espejo 1985, p. 269). For example, the contexts for which we develop information systems have changed considerably over the past 20 years. Mobile and ubiquitous information environments place the interaction between the user and the technology into a much broader environment, requiring us to address systems that are 
integrated into everyday activities through mobile phones, PDAs, and other handheld devices, as well as wearable computing devices (Lyytinen and Yoo 2002).

This paper addresses the evaluation of a particular aspect of ubiquitous information environments. Context-aware applications (CAAs) typically use location-based data and other contextual information to trigger predefined behavior (Schmidt et al. 1998). First generation CAAs included the notification agent, the meeting reminder agent, and callforwarding applications (Dey et al. 2001). Active badge systems (Weiser 1991) which can track wearers through particular locations, and global positioning systems that use databases of local information to provide details such as restaurant locations are other examples of CAAs.

In the same sense that DeSanctis and Poole (1994, p. 126) argue that "advanced information technologies have greater potential than traditional business computer systems to influence the social aspects of work," advanced CAAs have an even greater potential to influence the social aspects of everyday life. As Lyytinen and Yoo (2002) suggest, there are unique challenges posed by this type of system, in terms of design, use, and impact. In this environment, the technical and social aspects cannot be separated easily. There is a need for new ways of thinking about design, use, and impact, and new research approaches to study this type of system. As Galliers (1985, p. 281) reflected after the 1984 Colloquium, and is just as true today, we are faced with "an urgent need to develop our understanding of appropriate approaches to research in the IS field in a variety of different circumstances and with a variety of different objectives in mind."

This paper is part of a larger action research study exploring impact and methods for studying CAAs. To allow for a more targeted exploration of a proposed research approach for CAAs, a particular CAA is used. CABdriver (Context-Aware Backseat Driver) is a handheld interactive in-car concept currently in its first implemented version. The research approach we are taking is one that integrates the technical and social aspects of evaluating the use of a CAA. Although there are a number of approaches that fit this criterion, the approach selected for this analysis is adaptive structuration theory (AST). Lead users and repertory grids are integrated with the approach to provide early assessment of participants' perceptions of the evolving application concept.

\section{CABdriver}

Development of the CABdriver concept was initiated in January 2003, as a joint project with Saab, Mecel, and Vodafone. This first implementation of the CABdriver concept is a handheld game which uses contextual information to influence the game, thereby spawning social interaction between the player and the driver directly related to the changing context. The game is affected by points of interest (i.e., gas stations, tourist attractions, parking lots), traffic messages (i.e., accidents, road conditions, animal warnings), speed limit, actual car speed, fuel consumption, and driver work-load (a combination of anti-spin control and electronic stability program activity, braking, hard acceleration, navigation system indicating a turn is close-by, and recent use of the turn signal). 
In this paper, as well as in the broader research project, CABdriver is used as a tangible example of a context aware application which can be used to explore the applicability of a particular evaluation approach. This approach is described in the following section.

\section{RESEARCH APPROACH}

Traditionally, IS research has focused on assessing the impact of deployed technology, primarily within organizational settings. However, the contexts for which we develop information systems today increasingly consist of mobile and ubiquitous information environments, putting the interaction between the user and the technology into a much broader perspective. Rather than waiting for this area to develop independently from IS, IS researchers should establish an active role in identifying the methods and approaches used to study the technology itselfand its impact (Lyytinen and Yoo 2002; Orlikowski and Iacono 2001).

We are responding to this by exploring how an adaptation of action research (Baskerville and Wood-Harper 1996; Susman and Evered 1978), AST (DeSanctis and Poole 1994), repertory grids (Kelly 1955; Tan and Hunter 2002), and lead users (Von Hippel 1988) can help assess the impact of a CAA. Table 1 contains a summary of the characteristics of the research approach elements.

The representative features of action research that have so far come into play are (1) the collaborative initiative CABdriver, (2) highly involved researchers, and (3) the use of theory as a guide. As the larger study progresses, more detailed comments on the action research approach can be provided.

Out of several possible theoretical lenses, we are using AST (DeSanctis and Poole 1994) as it provides us with a rich description of the appropriation of technology and the impact this has. AST focuses not only on the social impact, but also on how technology itself affects this.

Table 1. Summary Research Approach Elements

\begin{tabular}{|l|l|l|}
\hline \multicolumn{1}{|c|}{ Characteristics } & \multicolumn{1}{|c|}{ Selected References } \\
\hline Action research & $\begin{array}{l}\text { - Involved researchers } \\
\text { - Collaborative } \\
\text { - Using theory as a guide } \\
\text { - Continuous reevaluation of theory } \\
\text { - Continuous reevaluation of application }\end{array}$ & $\begin{array}{l}\text { Susman and Evered } \\
(1978) \\
\text { Baskerville and Wood- } \\
\text { Harper (1996) }\end{array}$ \\
\hline AST & $\begin{array}{l}\text { - Social and technical aspects } \\
\text { - Appropriation process } \\
\text { - Impact of technology } \\
\text { - Predictive and explanatory }\end{array}$ & $\begin{array}{l}\text { DeSanctis and Poole } \\
(1994)\end{array}$ \\
\hline Repertory grids & $\begin{array}{l}\text { - Qualitative and quantitative aspects } \\
\text { - Capturing cognition }\end{array}$ & $\begin{array}{l}\text { Kelly (1955) } \\
\text { Tan and Hunter (2002) }\end{array}$ \\
\hline Lead users & - Early assessment of application & Von Hippel (1988) \\
\hline
\end{tabular}


Our use of AST differs somewhat from the traditional use of AST. First, our twomonth evaluation of the everyday use of CABdriver is not as long as traditional AST studies. Because we are evaluating a technology at an early stage, the amount of time spent on evaluation must be controlled. Second, this first implementation of the CABdriver concept is designed to directly influence one user, rather than the common case of multiple users of groupware systems. Still, the game is not a solitary game as it has been designed to be virtually impossible to play without interacting with and influencing the driver. Analysis of appropriation at this microlevel is something DeSanctis and Poole (1994, p. 133) identify as a logical starting-point "since it is in specific instances of discourse that the formation of new social structures begins." Third, AST has previously been used primarily in organizational settings, rather than in an everyday situation as is the case with CABdriver. Fourth, we are bringing the technology to the user and group, rather than studying an already existing technology. This means that we, as researchers and participants in the development, have strong structural features we hope to see, which thus forces us to take extra care to not overlook results that do not conform to our expectations.

In an effort to minimize researcher influence, we have incorporated the repertory grid technique (Kelly 1955; Tan and Hunter 2002) from personal construct theory (Kelly 1955 ) to assist in eliciting participants' personal constructs (also known as cognitive maps, technological frames, or mental models) related to AST. In addition, lead users (Von Hippel 1988) are included in the approach as they enable the CAA to be tested for design flaws prior to the main evaluation, something which is particularly vulnerable to neglect when researchers are involved in the development of the application.

\section{THE CABdriver SETTING}

Our initial strategy for evaluating CABdriver included three data collection points. At each point, we intended to individually interview each participant using repertory grids complemented by neutral probing questions (Reynolds and Gutman 1988). However, when applying this strategy to the lead user evaluation of CABdriver, it became evident that the strategy was too demanding for the participants, as each grid corresponding to particular constructs of the AST framework required close to one hour to complete. Based on this experience, the main evaluation of CABdriver instead uses two data collection points - one midway through and one after the evaluation period. Particular emphasis is put on the midway evaluation as the participants at that time have used the application long enough to have in-depth questions and experiences they can discuss with the researchers in order to better understand and further evaluate the application. Individual repertory grids capture how the task and environment are perceived by the participants while the appropriation part of AST is captured using qualitative (group) interviews (Patton2002; Wolcott2001). Post-evaluation, participants are asked to answer an in-depth open-ended questionnaire based on the results from the midway interview sessions. Through this two step process, initial results outlining the appropriation process and impact of CABdriver from a two month evaluation can be analyzed. Furthermore, participants are queried about their experiences from being subjected to the research approach. Together with the researchers' experiences, this enables the approach to be reevaluated for future improvement. 
Table 2. Lead User Assessments Using Repertory Grids

\begin{tabular}{|l|l|l|}
\hline $\begin{array}{l}\text { Action } \\
\text { research }\end{array}$ & $\begin{array}{l}\text { Core Assumptions } \\
\text { - IS researchers need to take an } \\
\text { active stance in the emerging } \\
\text { area of context-aware } \\
\text { applications. }\end{array}$ & - Too early in the study to discuss. \\
\hline AST & $\begin{array}{l}\text { - AST can provide a rich descrip- } \\
\text { tion of important aspects to } \\
\text { evaluate for emerging } \\
\text { technologies. }\end{array}$ & $\begin{array}{l}\text { - The rich description of AST provides } \\
\text { explanatory help rather than } \\
\text { predictive. }\end{array}$ \\
\hline $\begin{array}{l}\text { Repertory } \\
\text { grids }\end{array}$ & $\begin{array}{l}\text { The repertory grid technique can } \\
\text { reduce the influence of precon- } \\
\text { ceptions from strongly involved } \\
\text { researchers. }\end{array}$ & $\begin{array}{l}\text { - Repertory grids present participants } \\
\text { with a valuable record of the inter- } \\
\text { view session, enabling reconsi- } \\
\text { deration and further explanation on } \\
\text { issues often taken for granted. } \\
\text { Repertory grids present researchers } \\
\text { with an effective lens for } \\
\text { approaching recorded interview } \\
\text { sessions. }\end{array}$ \\
\hline $\begin{array}{l}\text { Lead } \\
\text { users }\end{array}$ & $\begin{array}{l}\text { - } \begin{array}{l}\text { Lead users can effectively test an } \\
\text { application concept for design } \\
\text { oversights prior to the main } \\
\text { evaluation. }\end{array} \\
\text { approaches to lead users prior to the } \\
\text { main evaluation is an effective way } \\
\text { to test the intended evaluation } \\
\text { strategy. }\end{array}$ \\
\hline
\end{tabular}

As this paper focuses on the time prior to the main evaluation, this work does not capture the experiences from the two month evaluation of CABdriver, only the assessments made from applying the approach to lead users of the application. The contribution of action research is, therefore, difficult to discuss at this stage, and we remain neutral to this particular method. The structured approach provided by AST appears to be useful as a guideline, but will be difficult to follow strictly. This implies that the explanatory powers of AST are likely more useful than any predictive powers. Unfortunately, it will be impossible to analyze conversations between participants (as is common in AST) due to the difficulties of continuously recording families for two months without imposing too much on their privacy and the everyday situation. Instead, repertory grids in combination with open-ended, semi-structured interviews and questionnaires based on the constructs of AST appear to be a useful substitute.

As indicated by Table 2, lead user assessments of CABdriver using repertory grids provided two unexpected benefits aside from acting as a tool to capture cognition: (1) during the interviews, participants found creating grids a great support for reflecting, comparing, and discussing issues they otherwise seldom considered, and (2) using the grids as an initial filter for how to approach the recorded sessions was highly effective and likely reduced the amount of researcher bias.

Finally, although the role of lead users was originally defined as testing the application for conceptual design flaws, the lead users also provided a valuable assessment of the data collection strategy, in our case resulting in a redesign. 


\section{CONCLUSION}

In this paper we have presented and briefly discussed the results from applying an adaptation of AST to an action research study, using the repertory grid technique and lead users. At this point (i.e., prior to the main evaluation of our CAA), we remain neutral to action research and AST as more data is needed to make a qualified discussion of their impact on the study. However, we strongly recommend using repertory grids and lead users to simultaneously assess evolving applications and research methods.

The overall project of studying CABdriver is still in the early stages. In order to continue the task ofestablishing an active role for IS researchers in the emerging mobile and ubiquitous information environments, additional implementations, theories, and evaluation approaches will be examined for suitability of use in this area.

\section{REFERENCES}

Baskerville, R. L., and Wood-Harper, A. T. "A Critical Perspective on Action Research as a Method for Information Systems Research,” Journal of Information Technology (11), 1996, pp. 235-246.

DeSanctis, G., and Poole, M. S. "Capturing the Complexity in Advanced Technology Use: Adaptive Structuration Theory,” Organization Science (5:2), 1994, pp. 121-147.

Dey, A. K.; Abowd, G. D.; and Salber, D. "A Conceptual Framework and a Toolkit for Supporting the Rapid Prototyping of Context-Aware Applications," Human-Computer Interaction (15), 2001, pp. 97-166.

Espejo, P. “Comment," in E. Mumford. R. Hirschheim, G. Fitzgerald, and A. T. Wood-Harper (Eds.), Research Methods in Information Systems, Amsterdam: North Holland, 1985, pp. $267-$ 269.

Galliers, R. D. "In Search of a Paradigm for Information Systems Research,” in E. Mumford. R. Hirschheim, G. Fitzgerald, and A. T. Wood-Harper (Eds.), Research Methods in Information Systems, Amsterdam: North Holland, 1985, pp. 281-297.

Kelly, G. The Psychology of Personal Constructs, Volumes 1 and 2, London: Routledge, 1955. Lyytinen, K., and Yoo, Y. "Research Commentary: The Next Wave of Nomadic Computing," Information Systems Research (13:4), 2002, pp. 377-388.

Mumford, E., Hirschheim, R., Fitzgerald, G., and Wood-Harper, A. T. Research Methods in Information Systems, Amsterdam: North-Holland, 1985.

Orlikowski, W. J., and Iacono, C. S. "Research Commentary: Desperately Seeking the 'IT' in IT Research: A Call to Theorizing the IT Artifact," Information Systems Research (12:2), 2001, pp. 121-134.

Patton, M. Q. Qualitative Research and Evaluation Methods (3 ${ }^{\text {rd }}$ ed.), London: Sage Publications, 2002.

Reynolds, T. J., and Gutman, J. "Laddering Theory, Method, Analysis, and Interpretation," Journal of Advertising Research, February-March 1988, pp. 11-31.

Schmidt, A.; Beigl, M.; and Gellersen, H-W. "There Is More to Context Than Location," Computers and Graphics (23), 1999, pp. 893-901.

Susman, G., and Evered, R. "An Assessment of the Scientific Merits of Action Research," Administrative Science Quarterly (23), December 1978, pp. 582-603. 
Tan, F. B., and Hunter, M. G. "The Repertory Grid Technique: A Method For The Study of Cognition In Information Systems," MIS Quarterly (26:1), 2002, pp. 39-57.

Von Hippel, E. The Sources of Innovation, New York: Oxford University Press, 1988.

Weiser, M. "The Computer for the 21st Century," Scientific American, September 1991, pp. 94104.

Wolcott, H. F. Writing Up Qualitative Research, London: Sage Publications, 2001.

\section{ABOUT THE AUTHORS}

Carl Magnus Olsson is a Ph.D. student at the Department of Informatics at Gothenburg University, Sweden. He conducts his research in the Telematics Group of the Viktoria Institute in Sweden and spends part of his time as a guest researcher at the Operations Management and Information Systems Department at the College of Business ofNorthern Illinois University, USA. His research is situated within ubiquitous information environments and investigates how contextaware applications may be evaluated and the impact these applications have on an individual and small group level. Prior to taking his position at the Viktoria Institute in September 2002, he worked at a computer consultancy company focusing on governmental agencies in Sweden and multinational engineering and telecommunications companies. He can be reached at cmo@viktoria.se.

Nancy L. Russo received her Ph.D. in Management Information Systems from Georgia State University in 1993. Since 1991, she has been a member of the Operations Management and Information Systems Department at Northern Illinois University. During 1998, she was a visiting professor in the Department of Accounting, Finance and Information Systems at University College Cork, Ireland. Dr. Russo is currently the Chair of the OMIS Department. In addition to on-going studies of the use and customization of system development methods in evolving contexts, her research has addressed web application development, the impact of enterprise-wide software adoption on the IS function, IT innovation, research methods, and IS education issues. Her work has appeared in Information Systems Journal, Journal of Information Technology, Information Technology \& People, Communications of the ACM, and other publications. Dr. Russo serves as secretary of the International Federation of Information Processing Working Group 8.2 on Information Systems and Organizations. She can be reached at nrusso@niu.edu. 